\title{
Effect of Isoproterenol on Regional Pulmonary Perfusion in the Reimplanted Lung of the Dog
}

\author{
Toyoharu Isawa, Takeo Teshima, Tomio Hirano, Akio \\ Ebina, Koichiro Shiraishi, Yoichi Fukuda and Kiyoshi \\ KonNo \\ Department of Medicine, the Research Institute for Tuberculosis \\ and Cancer, Tohoku University, Sendai 980
}

\begin{abstract}
Isawa, T., Teshima, T., Hirano, T., Ebina, A., Shiraishi, K., Fukuda, Y., and Konno, K. Effect of Isoproterenol on Regional Pulmonary Perfusion in the Reimplanted Lung of the Dog. Tohoku J. exp. Med., 1982, 136 (2), 163-168 — In the reimplanted lung lobe of the dog, regional pulmonary hypoxic vasoconstriction did not occur when isoproterenol was administered and the pharmacological action of isoproterenol in the reimplanted lung lobe was not antagonized by propranolol, whereas propranolol did block its action in the heart depressing the cardiac rate. - hypoxic vasoconstriction; isoproterenol; lung denervation; propranolol; reimplanted lung
\end{abstract}

In the previous communication we have reported that in the normal dog lungs isoproterenol reversed regional hypoxic vasoconstriction but that the action of isoproterenol was blocked by pretreatment with propranolol. Propranolol per se did not alter genuine regional vascular responses to regional alveolar hypoxia or hyperoxia (Isawa et al. 1981).

In the reimplanted dog lungs, however, pretreatment with propranolol did not block the action of isoproterenol to increase regional perfusion distribution in the hypoxic right upper lobe as reported in the following.

\section{Materials and Methods}

Six dogs with the reimplanted right lungs were studied. The experimental procedures were the same as described previously (Isawa et al. 1978a, b, 1981). Especially the use of medications and the sequence of studies were the same as adopted in the normal dogs as reported previously (Isawa et al. 1981) so that comparison of the data was possible between the normal and the denervated lung lobes. In brief, the right upper lobe was isolated by a balloon catheter under bronchoscopy and artificially ventilated with nitrogen $\left(\mathrm{N}_{2}\right)$, air or $60 \%$ oxygen $\left(\mathrm{O}_{2}\right)$ in $\mathrm{N}_{2}$, while the rest of the lungs was spontaneously breathing air. Assessment of regional perfusion distribution was done by measuring net radioactivity of the region divided by the total net radioactivity of the right and left lungs when the right upper lobe was artificially ventilated with $\mathrm{N}_{2}$, air and $60 \% \mathrm{O}_{2}$ in $\mathrm{N}_{2}$, respectively, and the values obtained served as controls. Then DL-isoproterenol $(0.1$

Received for publication, March 13, 1981.

Supported in part by Cancer Research Grant No. 101513 from the Ministry of Education, Science and Culture, Japan and a grant-in-aid from the Daiichi Radioisotope Laboratories, Ltd. 
w/v \%, $1 \mathrm{ml} /$ ampoule, Kaken Chemical Co., Ltd., Tokyo) was infused intravenously at the rate of $0.2 \mu \mathrm{g} / \mathrm{kg} / \mathrm{min}$ and the same procedures were repeated to assess regional perfusion. Then propranolol hydrochloride $(2 \mathrm{mg} /$ ampoule, Sumitomo Kagaku Kogyo Co., Ltd., Osaka) $1 \mathrm{mg} / \mathrm{kg}$ was infused over $10 \mathrm{~min}$ period. Following the administration of propranolol, infusion of DL-isoproterenol was repeated at the same rate as previously and perfusion distribution was again measured for each exchange gas of $\mathrm{N}_{2}$, air or $60 \%$ $\mathrm{O}_{2}$ in $\mathrm{N}_{2}$ for the right upper lobe.

Alveclar gas samples in the right upper lcbe, mixed expired gas samples from the rest of the lungs and arterial blood from the femoral artery were obtained for analysis of partial pressures of oxygen and carbon dioxide, and respiratory frequency and electrocardiogram were monitored. The paired $t$-test was used for statistical analysis.

\section{Results}

Perfusion percentages in the right upper lobe during the control period and the administration of isoproterenol before and after the pretreatment with propranolol are shown in Fig. 1. Regional perfusion in the right upper lobe increased from $5.9 \pm 0.4 \%$ (mean \pm s.E.M.) to $7.8 \pm 0.5 \% \quad(p<0.05)$ during the administration of isoproterenol and it then increased to $10.0 \pm 1.2 \%$ during the administration of isoproterenol following the pretreatment with propranolol, when the right upper lobe was artificially ventilated with $\mathrm{N}_{2}$. The increases during the administration of isoproterenol were statistically significant as compared with the control value $(p<0.05)$ but not significant from each other before and after the pretreatment with propranolol by paired $t$-test.

When the lobe was ventilated with either air or $60 \% \mathrm{O}_{2}$ in $\mathrm{N}_{2}$, there was no statistical difference in the regional perfusion in the right upper lobe before and after administration of isoproterenol or isoproterenol following the pretreatment

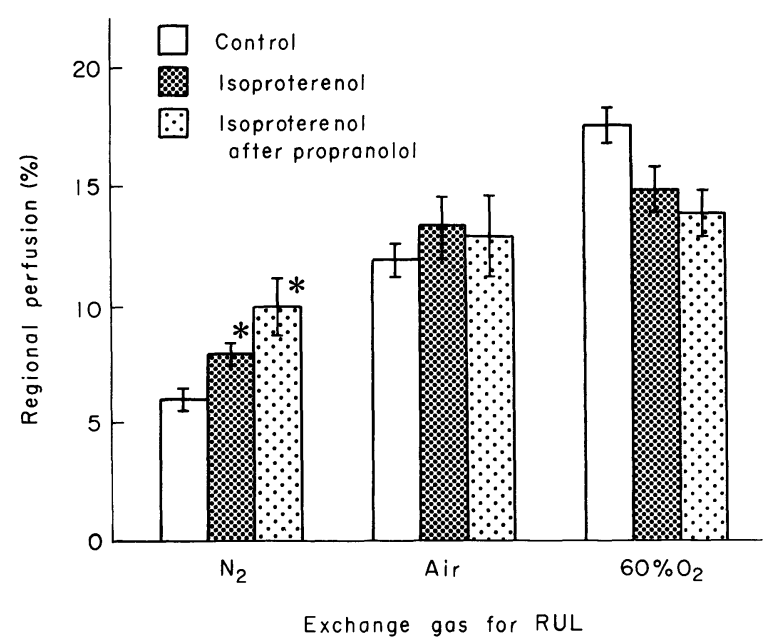

Fig. 1. Regional perfusion percentages in the right upper lobe during control period $(\square)$, and during the administration of isoproterenol before ( and after ( the pretreatment with propranolol. Mean \pm s.e.m. $n=6$. * Significantly different from control $(p<0.05)$. 
TABLE 1. Composition of the alveolar gas in the right upper lobe

\begin{tabular}{lcccccc}
\hline $\begin{array}{c}\text { Exchange gas } \\
\text { for right } \\
\text { upper lobe }\end{array}$ & \multicolumn{2}{c}{ Control } & \multicolumn{2}{c}{ Isoproterenol } & \multicolumn{2}{c}{$\begin{array}{c}\text { Isoproterenol after } \\
\text { propranolol }\end{array}$} \\
& $\begin{array}{c}\mathrm{P}_{\mathrm{AO} 2} \\
(\mathrm{mmHg})\end{array}$ & $\begin{array}{c}\mathrm{P}_{\mathrm{ACO} 2} \\
(\mathrm{mmHg})\end{array}$ & $\begin{array}{c}\mathrm{P}_{\mathrm{AO} 2} \\
(\mathrm{mmHg})\end{array}$ & $\begin{array}{c}\mathrm{P}_{\mathrm{ACO} 2} \\
(\mathrm{mmHg})\end{array}$ & $\begin{array}{c}\mathrm{P}_{\mathrm{AO} 2} \\
(\mathrm{mmHg})\end{array}$ & $\begin{array}{c}\mathrm{P}_{\mathrm{ACO} 2} \\
(\mathrm{mmHg})\end{array}$ \\
& $40.9 \pm 1.4$ & $53.8 \pm 1.4$ & $52.9 \pm 1.9$ & $54.9 \pm 0.8$ & $37.0 \pm 0.9$ & $55.4 \pm 0.8$ \\
$\mathrm{~N}_{2}$ & $77.6 \pm 1.4$ & $55.6 \pm 0.8$ & $72.6 \pm 2.4$ & $55.5 \pm 0.4$ & $80.3 \pm 4.4$ & $56.3 \pm 0.9$ \\
$\mathrm{Air}$ & $322.6 \pm 7.5$ & $55.1 \pm 0.5$ & $304.7 \pm 6.4$ & $54.9 \pm 0.4$ & $316.9 \pm 15.4$ & $56.0 \pm 1.1$
\end{tabular}
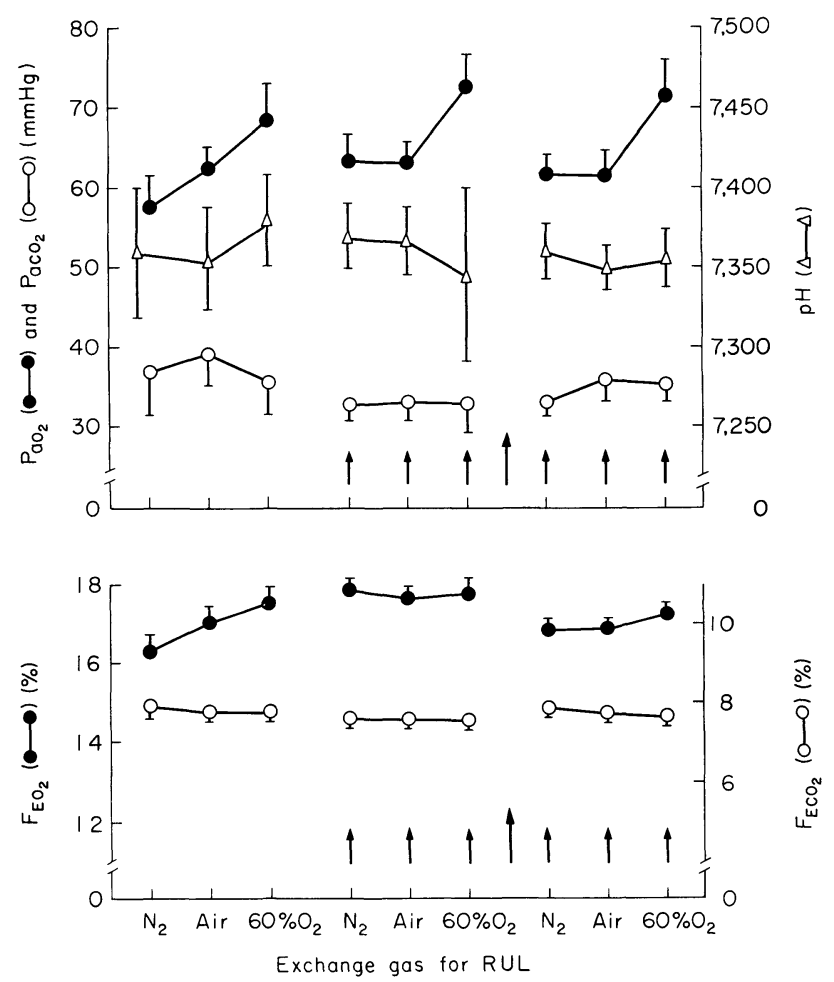

Fig. 2. Changes in the arterial blood gas (top panel) and the mixed expired gas (bottom panel) during the control period and during the administration of isoproterenol before and after the pretreatment with propranclol. Small arrows indicate the administration of isoproterenol and the larger one the administration of propranolol.

with propranolol. When isoproterenol was infused, alveolar $\mathrm{O}_{2}$ tension in the right upper lobe ventilated with $\mathrm{N}_{2}$ was significantly higher than the control period as shown in Table 1, but blood gas data during the administration of isoproterenol were not very different from the controls and so were oxygen and carbon dioxide fractions in the mixed expired gas $\left(\mathrm{F}_{\mathrm{EO}_{2}}\right.$ and $\mathrm{F}_{\mathrm{ECO}_{2}}$, respectively) as shown in Fig. 2.

Respiratory frequency and cardiac rate were both increased following the administration of isoproterenol, but after the pretreatment with propranolol both 


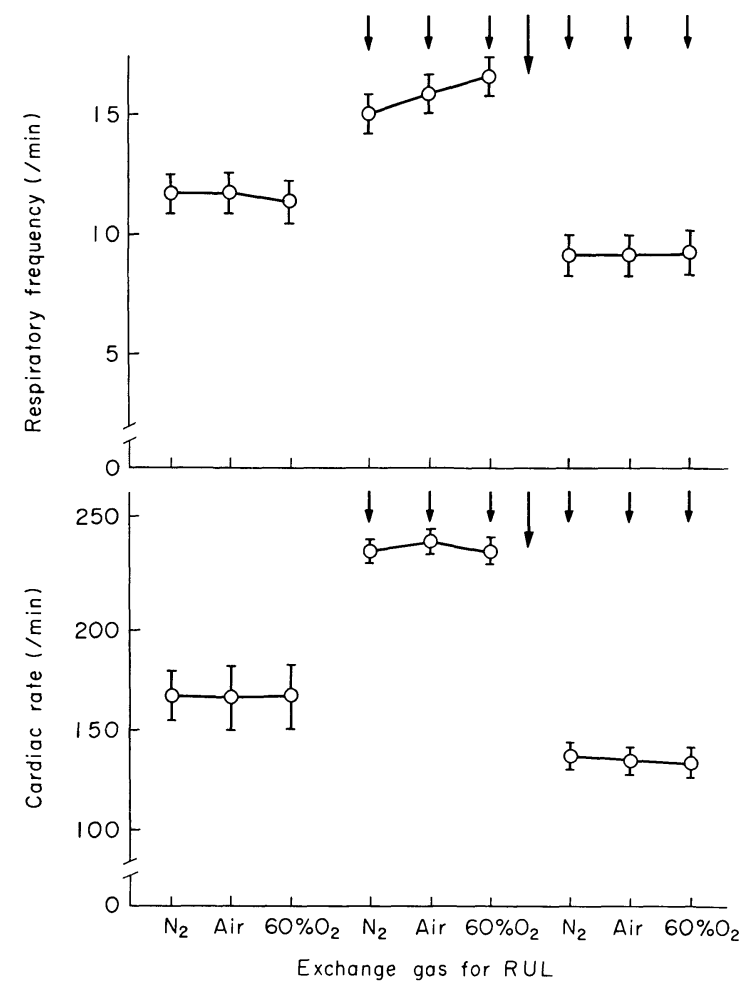

Fig. 3. Changes in the respiratory frequency and the cardiac rate during the control period and the administration of isoproterenol before and after the administration of propranolol. Small arrows indicate the administration of isoproterenol and the large one the administration of propranolol.

of them significantly decreased even following the administration of isoproterenol as shown in Fig. 3.

\section{Discussion}

There was no difference between the normal and the reimplanted or denervated lungs in the regional vascular responses to regional alveolar hypoxia and hyperoxia (Isawa et al. 1978b), but hyperoxic vasodilatation and/or recruitment of the pulmonary vascular beds was somewhat potentiated in the denervated lung under concurrent alveolar hypercapnia, although regional perfusion was still mainly regulated by the regional alveolar oxygen tension $\left(\mathrm{P}_{\mathrm{AO}_{2}}\right)$ (Isawa et al. 1980). Under alveolar hypoxia, however, the administration of isoproterenol abolished the regional hypoxic vasoconstriction, but if propranolol was given before the administration of isoproterenol, regional hypoxic vasoconstriction remained unaffected by isoproterenol. Propranolol per se, however, didn't show any effect on pulmonary vascular responses to different alveolar oxygen tension (Isawa et al. 1981). 
In the present study of the reimplanted lungs the administration of isoproterenol further increased regional pulmonary perfusion in the hypoxic lung lobe despite the pretreatment with propranolol. There would be a question whether this is due to a chance error or due to the fixed sequence of experimental procedures. If the results are influenced by such factors, however, similar influences would have occurred in the normal lungs. In the latter, pretreatment with propranolol did block the effect of isoproterenol to increase regional perfusion distribution in the hypoxic right upper lobe (Isawa et al. 1981). Previously we changed the sequence of administration of exchange gases of different oxygen concentration for the right upper lobe, but perfusion data were not influenced by the sequence of administration (Isawa et al. 1978b). On the other hand, they were clearly influenced by the difference in oxygen concentrations in the exchange gases for the right upper lobe. Furthermore, propranolol itself didn't induce any additional effect on the distribution of the pulmonary arterial perfusion in the normal lungs unless isoproterenol was administered (Isawa et al. 1981) and we took it for granted that propranolol would act similarly also in the reimplanted lungs, but were surprised on finding the fact that propranolol didn't seem to block the action of isoproterenol in the hypoxic right upper lobe.

The cardiac rate, however, increased when isoproterenol alone was given, but it remained depressed if isoproterenol was administered following the pretreatment with propranolol. In the dog with the reimplanted right lung, the right lung was the only organ which was once surgically removed outside of the thorax and reimplanted, thus making itself denervated. The other organs including the heart were not denervated. In such preparation as those used in this experiment, the cardiac response was similar to that in dogs with normal lungs as reported previously (Isawa et al. 1981). In the heart the $\beta$-adrenergic receptors were naturally blocked by propranolol in the dogs with the reimplanted right lungs as well, but the $\beta$-adrenergic receptors in the reimplanted lungs didn't seem to have been blocked by propranolol. The true reason why this difference between the reimplanted and the normal lungs has occurred, however, remains open to question, and further studies would be required to elucidate this strange phenomenon.

\section{Acknowledgment}

We are grateful to Dr. Shigefumi Fujimura of the Department of Surgery of this Institute for performing reimplantation of the right lung, Ms. Yuko Kobayashi and Shoko Sakamoto for their clerical assistance in the preparation of the manuscript, and Dr. Hiroshi Ogawa of the Daiichi Radioisotope Lab., Ltd. for his kind support of this study.

\section{References}

1) Isawa, T., Teshima, T., Hirano, T., Shiraishi, K., Matsuda, T. \& Konno, K. (1978a) Regulation of regional perfusion distribution in the lungs. Experimental model and effect of alveolar pressure. Tohoku J. exp. Med., 124, 33-46.

2) Isawa, T., Teshima, T., Hirano, T., Shiraishi, K., Matsuda, T. \& Konno, K. (1978b) Regulation of regional perfusion distribution in the lungs. Effect of regional oxygen concentration. Amer. Rev. respir. Dis., 118, 55-63. 
3) Isawa, T., Teshima, T., Hirano, T., Shiraishi, K., Matsuda, T. \& Konno, K. (1980) Effect of alveolar hypercapnia on regional pulmonary perfusion. Tohoku J. exp. Med., 132, 187-197.

4) Isawa, T., Teshima, T., Hirano, T., Ebina, A., Shiraishi, K. \& Konno, K. (1981) Effect of isoproterenol on regional pulmonary perfusion and its blockade by propranolol. Tohoku J. exp. Med., 134, 59-69. 